\title{
Sarcocystis cruzi (Apicomplexa: Sarcocystidae) no cachorro-do-mato (Cerdocyon thous) ${ }^{1}$
}

\author{
Janaina S. Rodrigues ${ }^{2}$, Gisele S. Meireles ${ }^{3}$, Paulo R. Carvalho Filho ${ }^{3}$, Carlos \\ T. Ribeiro ${ }^{3}$, Walter Flausino ${ }^{4}$ e Carlos Wilson G. Lopes ${ }^{4 *}$
}

\begin{abstract}
Rodrigues J., Meireles G.S., Carvalho Filho P.R., Ribeiro C.T., Flausino W. \& Lopes C.W.G. 2008. [Sarcocystis cruzi (Apicomplexa: Sarcocystidae) in the crab-eating fox (Cerdocyon thous).] Sarcocystis cruzi (Apicomplexa: Sarcocystidae) no cachorro-do-mato (Cerdocyon thous). Pesquisa Veterinária Brasileira 28(11):561564. Departamento de Parasitologia Animal, Instituto de Veterinária, Universidade Federal Rural do Rio de Janeiro, Seropédica, RJ 23890-000, Brazil. E-mail: lopescwg@ ufrrj.br

Sporocysts of Sarcocystis were identified in feces samples of a crab-eating fox, and were orally given to a suckling calf; after 3 months of infection, sarcocysts morphologically similar to Sarcocystis cruzi were observed in cardiac and skeletal striated muscles. The cardiac muscles of this calf were orally given to a puppy free of coccidia, that shed sporocysts in its feces. with a prepatent and patent period of 11 and 12 days after infection, respectively. To compare the morphology of the sporocysts and cysts, a second puppy was fed on bovine cardiac muscles infected naturally, and sporocysts identical to those shed by the first dog were recovered from its feces. In spite of the significant difference between sporocysts found in the mucosa of the crab-eating fox and those shed by the first and second puppies, the species observed in this study was considered to be Sarcocystis cruzi, based on size of the sporocyts, morphology of the cyst wall, and the pray-predator cycle.
\end{abstract}

INDEX TERMS: Sarcocystis cruzi, sporocysts, cysts, crab-eating fox, Cerdocyon thous, dogs, cattle.

RESUMO.- Esporocistos de Sarcocystis foram identificados nas amostras fecais de um cachorro-do-mato. Eles foram dados por via oral para um bezerro em aleitamento, sendo observados cistos com morfologia compatível com os de Sarcocystis cruzi na musculatura cardíaca e esquelética, três meses após a infecção. Musculatura cardíaca deste bezerro foi dada para um segundo cão doméstico livre de coccídios, que eliminou esporocistos compatíveis com os de Sarcocystis em suas fezes, tendo com períodos pré-patente e patente 11 e 12 dias após a

\footnotetext{
${ }^{1}$ Recebido em 3 de agosto de 2007.

Aceito para publicação em 4 de outubro de 2008.

${ }^{2}$ Departamento de Parasitologia Animal (DPA), Instituto de Veterinária (IV), Universidade Federal Rural do Rio de Janeiro (UFRRJ)., Seropédica, RJ 23890-000, Brasil. Bolsista de Iniciação Científica do CNPq.

${ }^{3}$ Curso de Pós-Graduação em Ciências Veterinárias, UFRRJ. Bolsistas da CAPES.

${ }^{4}$ DPA, IV, UFRRJ. Bolsistas do CNPq. *Autor para correspondência: lopescwg@ufrrj.br
}

infecção respectivamente. Para comparar a morfologia dos esporocistos e cistos, um segundo cão, também livre de coccídios, foi alimentado com musculatura cardíaca de um bovino infectando naturalmente e positivo para cistos de $S$. cruzi. Esporocistos compatíveis com os eliminados pelo primeiro cão foram encontrados nas fezes. Apesar dos esporocistos eliminados pelo cachorro-do-mato serem significativamente diferentes dos eliminados pelos cães infectados experimentalmente, pode se considerar com base na morfologia dos esporocistos, cistos e na transmissão biológica que a espécie encontrada nas fezes do cachorro-do-mato é Sarcocystis cruzi.

TERMOS DE INDEXAÇÃO: Sarcocystis cruzi, esporocistos, cistos, cachorro-do-mato, Cerdocyon thous, cães, bovino.

\section{INTRODUÇÃO}

Os animais silvestres são extremamente importantes na participação de infecções por coccídios (Lopes \& Pereira 1987, Lopes 2002). Entre eles, o cachorro-do-mato Cerdocyon thous assume papel preponderante na trans- 
missão de coccídios por ser encontrado na América do Sul até o norte da Argentina exceto na bacia amazônica. Habita comumente áreas abertas, alteradas, campos e florestas (Pró-Carnívoros 2007).

Alguns destes animais têm uma relação muito estreita com os animais domésticos e acabam sendo parasitados, aparentemente, pelas mesmas espécies de coccídios. As doenças surgem ou recrudescem quando animais silvestres e domésticos passam a utilizar o mesmo território, principalmente onde a agropecuária é desenvolvida de maneira extensiva (Fayer 1980, Lopes 2002).

Diversas espécies de carnívoros silvestres são hospedeiras definitivas de Sarcocystis encontrados nos animais domésticos. Coiotes, raposas e guaxinins podem ser hospedeiros de Sarcocystis cruzi (Rommel et al. 1974, Fayer \& Johnson 1975, Fayer et al. 1976), raposas de S. tenella (Ashford 1977) e cachorro-do-mato de S. capracanis, acometendo os caprinos (Pereira \& Lopes 1982).

Este trabalho tem como objetivo contribuir para o conhecimento da importância do cachorro-do-mato (Cerdocyon thous) na disseminação de esporocistos de Sarcocystis cruzi no Brasil.

\section{MATERIAL E MÉTODOS Origem dos animais e obtenção dos esporocistos de Sarcocystis}

Segmentos do intestino delgado, duodeno, jejuno e íleo de um cachorro-do-mato (Cerdocyon thous) foram coletados, sendo que este animal veio a óbito de causa não identificada no Centro de Triagem de Animais Selvagens (Cetas/lbama/RJ), localizado no município de Seropédica, RJ. Este animal apresentava esporocistos de Sarcocystis no exame coprológico (Menezes \& Lopes 1995) sendo as amostras de intestino delgado fixadas em formol $10 \%$ tamponado, $\mathrm{pH} 7,2$, para a pesquisa de esporocistos. Após a coleta deste material, a mucosa dos segmentos intestinais foi raspada com uma lâmina de vidro e submetida à digestão conforme Dubey (1998) e a separação e obtenção de esporocistos conforme Menezes \& Lopes (1995).

Um bezerro macho, de 12 dias de idade ainda em período de aleitamento, oriundo de uma propriedade rural localizada na zona oeste do município do Rio de Janeiro e mantido em um bezerreiro da Estação para Pesquisa Parasitológica W.O. Neitz da UFRRJ. Ao mesmo tempo, dois cães domésticos recentemente desmamados, e considerados livres de coccídios pelo exame coprológico segundo Menezes \& Lopes (1995). foram mantidos em canis na mesma estação experimental, tendo recebido alimentação adequada à idade e água ad libitum.

\section{Infecção experimental}

Um bezerro recebeu por via oral $1,3 \times 10^{4}$ esporocistos $/ 5 \mathrm{~mL}$, obtidos do raspado de mucosa do intestino delgado do cachorrodo-mato. Após 120 dias da infecção experimental este bezerro foi submetido a eutanásia, conforme normas do Conselho Regional de Medicina Veterinária do Rio de Janeiro (CRMV-RJ 2003) e amostras de tecidos da musculatura cardíaca foram fixadas em formol a $10 \%$, tamponado em $\mathrm{pH} 7,2$, para análise histológica. $\mathrm{O}$ restante da musculatura cardíaca foi triturada e fornecida como alimento a um dos cães (Cão I) para determinação da especificidade da espécie de Sarcocystis encontrada no cachorro-do-mato (Odening 1998). O Cão II foi alimentado com musculatura cardíaca triturada, obtida no matadouro de Barra Mansa, RJ, e positiva para cistos de Sarcocystis cruzi. Para este animal, também foram utilizados os mesmos procedimentos relatados para o cão I. Ao final do experimento, os cães foram submetidos a eutanásia, em conformidade com normas do CRMV-RJ (2003).

\section{Procedimentos laboratoriais}

Exames de fezes de ambos os cães foram realizados diariamente por um período de 21 dias após a infecção experimental para determinação do período pré-patente e patente. Para a obtenção dos esporocistos eliminados nas fezes foi utiliza a técnica de centrífugo-flutuação em solução saturada de sacarose (Menezes \& Lopes 1995) e para a mensuração dos mesmos foi utilizado um microscópio binocular (Carl Zeiss) com ocular micrométrica SK-15X (PZO).

Os exames histológicos das amostras dos segmentos do intestino delgado do cachorro-do-mato, dos cães domésticos, do músculo cardíaco procedente do bezerro infectado experimentalmente e do coração de bovino infectado naturalmente e obtido no matadouro foram processados, incluídos em parafina e corados em Hematoxilina-Eosina (HE) e PAS conforme técnica descrita por Behmer et al. (1976). As fotografias foram tiradas com auxílio de uma câmara digital (Sony) em um microscópio triocular (Zeiss, Jena) As análises de tendência central dos esporocistos e o teste $t$ de Tukey foram determinados com base em Sampaio (2002).

\section{RESULTADOS E DISCUSSÃO}

As dimensões dos esporocistos (Fig.1a,b) oriundos do raspado de mucosa do cachorro-do-mato e dos cães infectados experimentalmente estão no Quadro 1. Houveram diferenças significativas em nível de $5 \%$ no diâmetro maior dos esporocistos quando compara o eliminado pelo cachorro do mato em comparação aos eliminados pelos cães experimentalmente infectados. Poliformismo semeIhante foi observado por Pereira et al. (2001) ao estudar as variações morfométricas de oocistos de Hammondia heydorni eliminados tanto por cachorro-do-mato como por cães domésticos infectados experimentalmente. Com base na morfometria dos esporocistos e morfologia dos cistos encontrados nas células da musculatura cardíaca e na especificidade quanto aos hospedeiros involvidos, cão e bovino, infectados experimentalmente com esporocistos do cachorro do mato são semelhantes as citações de Fayer (1980), Tenter (1995) e Odening (1998) que o caracteriza como Sarcocystis cruz; além dos períodos, pré-patente e patente serem semelhantes aos observados por Botelho \& Lopes (1984) e Figueiredo et al. (1991) para a mesma espécie. Além disso, os cistos encontrados na infecção experimental do bezerro com os esporocistos procedentes do cachorro-do-mato (Fig.2a) foram semelhantes morfologicamente aos observados nas células da musculatura estriada cardíaca obtida de um coração bovino com infecção natural (Fig.2b) e sendo compatível com a descrição morfológica descrita por Figueiredo et al. (1991) em infecções naturais de células 

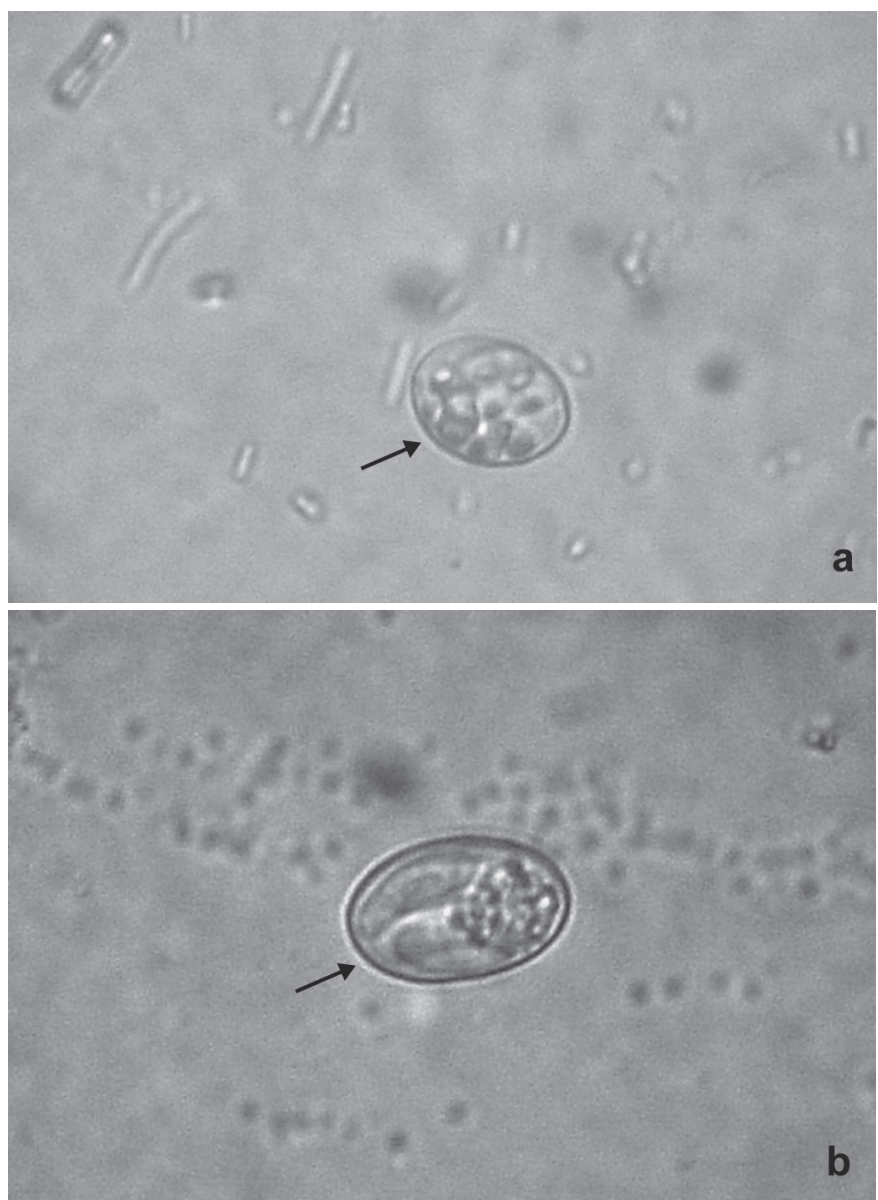

Fig.1. Esporocistos $(\rightarrow)$ de Sarcocystis cruzi: origem (a) cachorro-do-mato, (b) cão doméstico. Solução saturada de Açúcar, obj.100x.

da musculatura estriada cardíaca de um bovino, caracterizando-se o cisto por ter uma parede externa fina.

$\mathrm{Na}$ avaliação histopatológica da mucosa intestinal do cachorro-do-mato que veio a óbito no CETAS/lbama o grau de autólise observado, dado ao longo período entre a sua morte e a necrópsia prejudicou a análise, porém esparsos oocistos podiam ser observados. Da mesma maneira, acentuado número de oocistos esporulados

Quadro 1. Aspectos comparativos dos isolados de cachorrodo-mato e de cão doméstico para Sarcocystis cruzi

\begin{tabular}{lcrr}
\hline \multicolumn{1}{c}{$\begin{array}{c}\text { Esporocistos } \\
(\mathrm{mm})^{\mathrm{a}}\end{array}$} & \multicolumn{3}{c}{ Hospedeiro definitivo } \\
\cline { 2 - 4 } & $\begin{array}{c}\text { Cachorro- } \\
\text {-do-mato }\end{array}$ & \multicolumn{2}{c}{ Cão doméstico } \\
\hline Diâmetro maior & $14,84 \pm 0,94^{\mathrm{x}}$ & $17,87 \pm 0,80^{\mathrm{y}}$ & $17,44 \pm 0,82^{\mathrm{y}}$ \\
Diâmetro menor & $11,29 \pm 1,88^{\mathrm{y}}$ & $12,03 \pm 0,59^{\mathrm{y}}$ & $11,60 \pm 0,66^{\mathrm{y}}$ \\
Índice morfológico & $1,31 \pm 0,04^{\mathrm{y}}$ & $1,48 \pm 0,06^{\mathrm{y}}$ & $1,50 \pm 0,05^{\mathrm{y}}$
\end{tabular}

a Número de 10 esporocistos medidos. Letras diferentes $(x, y)$ na mesma linha significantes em nível de $5 \%$ pelo teste t de Tukey.

b Infectado experimentalmente com cistos de um bovino que recebeu esporocistos do cachorro do mato.

c Infectado experimentalmente com cistos de um bovino infectado naturalmente.
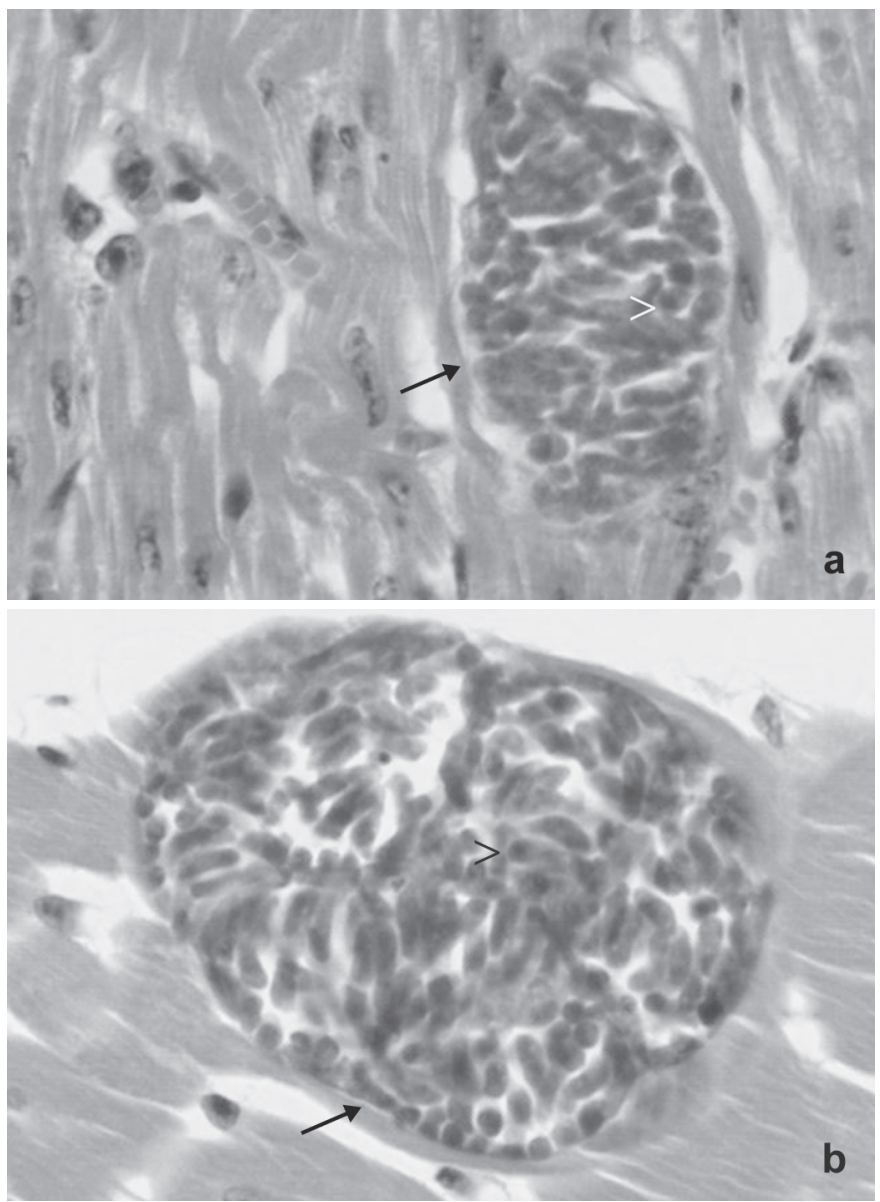

Fig.2. Cistos de Sarcocystis cruzi nas células da musculatura estriada cardíaca de bovino, origem: (a) infecção experimental com esporocistos do cachorro-do-mato e (b) infecção natural. Parede externa do cisto fina $(\leftarrow)$ e presença de bradizoítas. HE, obj.40x.

(Fig.3) puderam ser vistos abaixo da camada epitelial do intestino delgado nos Cães I e II infectados experimentalmente, porém sempre localizados nas extremidades das vilosidades intestinais. Não foram observadas lesões dignas de nota associadas à infecção por Sarcocystis, que segundo Fernando (1982), as lesões causadas por Sarcocystis são mais freqüentemente observadas nos hospedeiros intermediários, associadas às formas merogônicas localizadas no endotélio dos vasos sangüíneos, o que faz dos canídeos excelentes hospedeiros definitivos por não adoecerem da infecção e eliminarem grande quantidade de esporocistos em suas fezes.

Com base nos dados obtidos, os esporocistos encontrados nas fezes do cachorro-do-mato são da espécie Sarcocystis cruzi por ter esta espécie ter como hospedeiros definitivo e intermediário canídeos e bovinos respectivamente o que foi determinado experimentalmente por este trabalho.

\section{REFERÊNCIAS}

Behmer O.A., Tolosa E.M.C. \& Freitas Neto A.G. 1976. Manual de Técnicas para Histologia Normal e Patológica. EDART, São Paulo. 256p. 

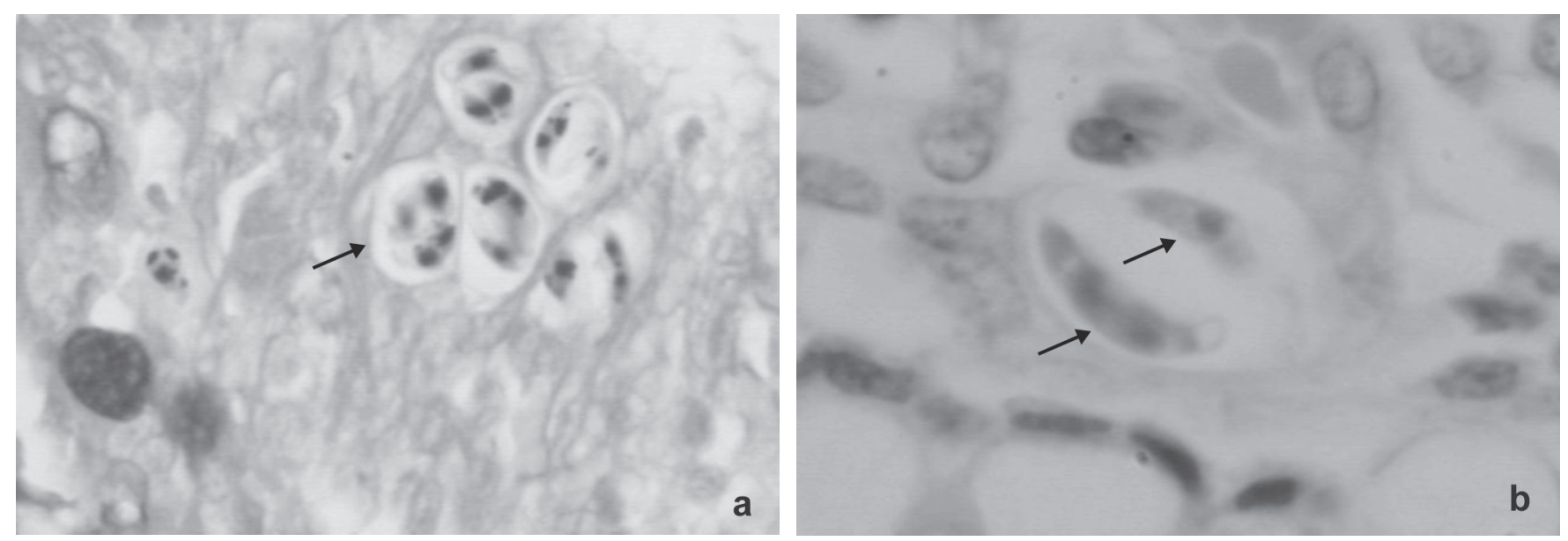

Fig.3. Íleo do cão doméstico infectado experimentalmente com cistos do bovino infectado experimentalmente. Esporocistos com esporozoítas $(\rightarrow)$ localizados na lâmina própria de uma vilosidade. PAS, (a) obj.20x, (b) obj.100x.

Botelho G.G. \& Lopes C.W.G. 1984. Esporocistos de Sarcocystis cruzi (Apicomplexa: Sarcocystidae) em linfonodos mesentéricos de cães. Arqs Univ. Fed. Rur., Rio de J., 7:87-88.

CRMV-RJ 2003. Resoluções. Acesso: <www. crmvrj.com.br/legisla/text/ res714.htm>. Capturado em 22 jul. 2003.

Dubey J.P. 1998. Refinement of pepsin digestion method for isolation of Toxoplasma gondii from infected tissues. Vet. Parasitol., 74: 75-77.

Fernando M.A. 1982. Pathology and pathogenicity, p.287-327. In: Long P.L. (Ed.), The Biology of the Coccidia. University Park Press, Baltimore.

Figueiredo P.C., Lopes C.W.G. \& Serra-Freire N.M. 1991. Espécies do gênero Sarcocystis Lankaster, 1882 (Apicomplexa: Sarcocystidae), parasitas de ruminantes domésticos que têm o cão como hospedeiro definitivo. Arqs Univ. Fed. Rur., Rio de J., 14:1-12.

Lopes C.W.G. 2004. O gênero Sarcocystis (Lankaster, 1882) (Apicomplexa: Sarcocystidae), uma questão a ser reavaliada no Brasil. Revta Bras. Parasitol. Vet. 13(Supl.1):14-16.

Lopes C.W.G. \& Pereira M.J.S. 1987. Infection of a crab-eating fox
(Cerdocyon thous) by Hammondia heydorni (Apicomplexa: Sarcocystidae) from a goat. Arqs Univ. Fed. Rur., Rio de J., 10:1-2.

Menezes R.C.A.A. \& Lopes C.W.G. 1995. Epizootiologia da Eimeria arloingi em caprinos na microrregião serrana-fluminense, Rio de Janeiro, Brasil. Revta Univ. Rural, Ser. Ciênc. Vida, 17:5-12

Odening K. 1998. The present state of espécies-systematics in Sarcocystis Lankaster, 1882 (Protista, Sporozoa, Coccidia). Syst. Parasitol. 41:209-233.

Pereira M.J.S. \& Lopes C.W.G. 1982. The crab-eating fox (Cerdocyon thous) as a final host for Sarcocystis capracanis (Apicomplexa: Sarcocystidae) in Brazil. Arqs Univ. Fed. Rur., Rio de J. 10:75-78.

Pró-Carnívoros 2007. Cachorro-do-mato. Acesso: <www.procarnivoros.org.br/ animais_cac.htm>. Capturado em 18 jul. 2007.

Sampaio I.B.M. 2002. Estatística Aplicada à Experimentação Animal. $2^{\mathrm{a}}$ ed. FEPMVZ, Belo Horizonte. 265p.

Terter A. 1995. Current research on Sarcocystis species of domestic animals. Int. J. Parasitol., 25:1311-1330 